\title{
The female condom in Ghana: Exploring the current state of affairs and gauging potential for enhanced promotion
}

Reshma Naik

Martha Brady

Population Council

Follow this and additional works at: https://knowledgecommons.popcouncil.org/departments_sbsr-pgy

Part of the Demography, Population, and Ecology Commons, Family, Life Course, and Society Commons, Gender and Sexuality Commons, International Public Health Commons, Medicine and Health Commons, and the Women's Health Commons How does access to this work benefit you? Let us know!

\section{Recommended Citation}

Naik, Reshma and Martha Brady. 2008. "The female condom in Ghana: Exploring the current state of affairs and gauging potential for enhanced promotion." Accra: Population Council. 


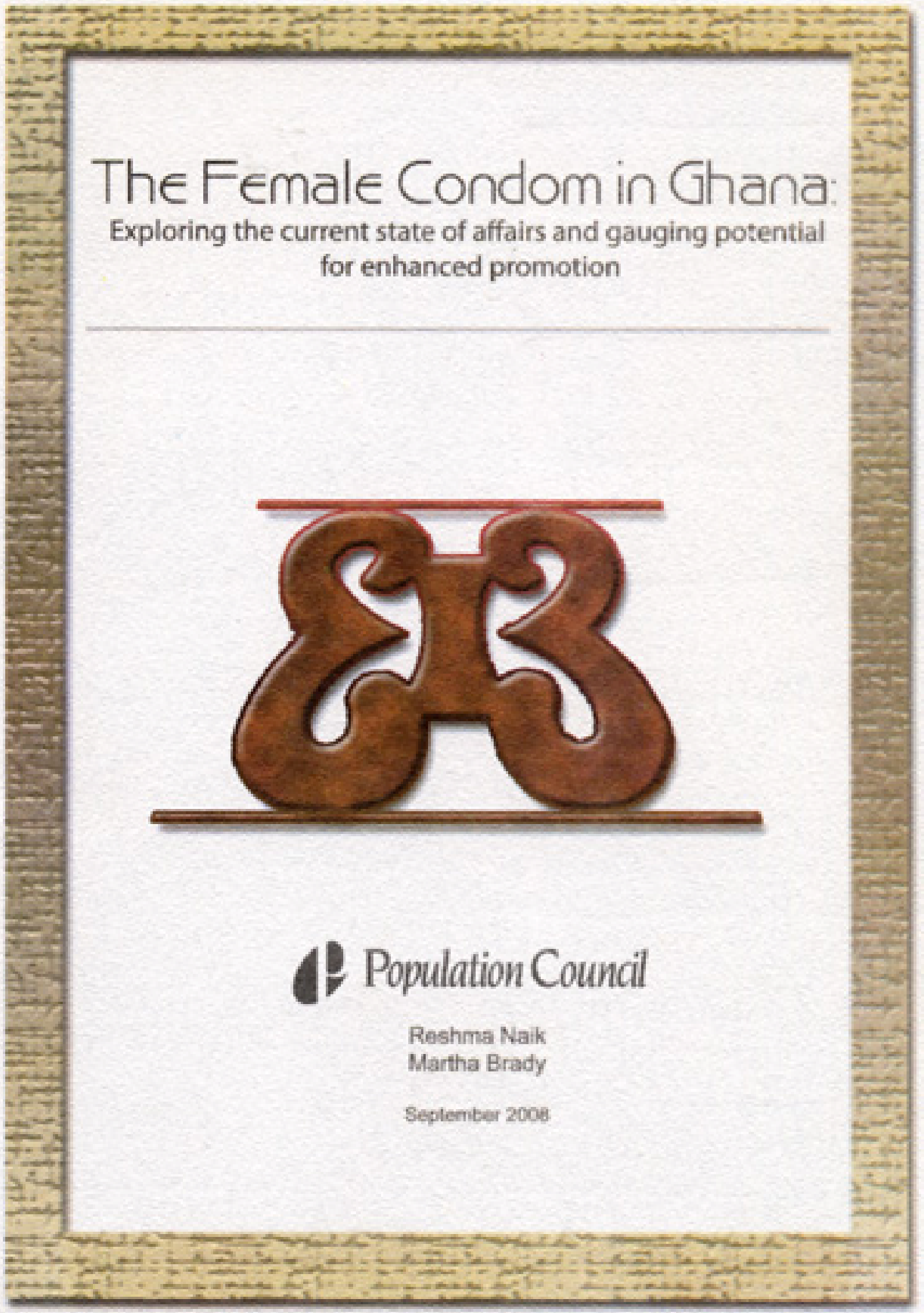




\section{The Female Condom in Ghana: \\ Exploring the current state of affairs and gauging potential for enhanced promotion}

(2) Population Council

Reshma Naik

Martha Brady

September 2008 


\section{(2) Population Council}

Research that makes a difference

The Population Council seeks to improve the health and well-being of the world's poorest and most vulnerable people, identifying challenges that have previously been neglected. The Council conducts research worldwide to improve policies, programs, and products in three areas: HIV and AIDS; poverty, gender, and youth; and reproductive health.

The Female Condom mapping exercise and this report was made possible through supported provided by the Royal Danish Ministry of Foreign Affairs.

(C) 2008 The Population Council, Inc. 


\section{Table of content}

Table of Content

Acknowledgements

Abbreviations

Executive Summary

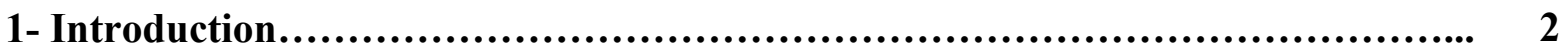

2- Historical Context................................................................... 4

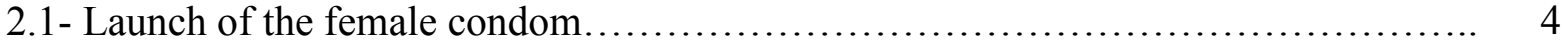

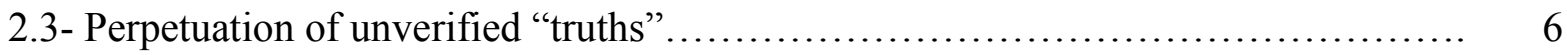

3- Current State of Affairs........................................................ 6

3.1- Interest and support for further promotion................................... 7

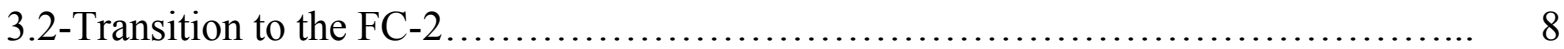

4- Procurement, Supply, and Demand....................................... 8

4.1- Procurement mechanisms.................................................. 8

4.2- Challenges with regard to demand for the female condom................... 11

4.3-Challenges with regard to supply of the female condom $\ldots \ldots \ldots \ldots \ldots \ldots \ldots \ldots \ldots . .11$

5- Conclusions and Recommendations........................................ 12 


\section{Acknowledgements}

We would like to acknowledge the support of Dr.Gloria Quansah Asare, Ag. Director of the Family Health Division (Ghana Health Service) for her assistance in facilitating this assessment.

The contribution of all stakeholders interviewed during the data collection process is deeply appreciated. Our special gratitude also goes to the Population Council Accra staff, particularly Placide Tapsoba, Kobina Bainson, Clétus Adohinzin and Abena Gyau for making this assessment possible. 


\section{Abbreviations}

$\begin{array}{ll}\text { AIDS } & \text { Acquired Immunodeficiency Syndrome } \\ \text { DHS } & \text { Demographic and Health Survey } \\ \text { GHS } & \text { Ghana Health Service } \\ \text { HIV } & \text { Human Immune Virus } \\ \text { IUD } & \text { Intrauterine Device } \\ \text { RH } & \text { Reproductive Health } \\ \text { RTIs } & \text { Reproductive Tract Infections } \\ \text { STIs } & \text { Sexually Transmitted Infections } \\ \text { STD } & \text { Sexual Transmitted Disease } \\ \text { IEC } & \text { Information, Education and Communication } \\ \text { FCPC } & \text { Female Condom Planning Committee } \\ \text { FC } & \text { Female Condom } \\ \text { NACP } & \text { National AIDS Control Programme }\end{array}$




\section{Executive Summary}

The female condom (FC) is the only safe and effective female-initiated method that provides simultaneous protection against unintended pregnancy as well as sexually transmitted infections (STIs), including HIV/AIDS. ${ }^{1}$ An exploratory exercise was conducted by the Population Council to gain an understanding of the current and historical landscape of female condom (FC) procurement, distribution, and programming in Ghana and to explore the viability of enhancing national FC promotion. The exercise was conducted by a Population Council consultant who interviewed 21 key stakeholders representing 16 relevant groups or institutions in Ghana.

The exercise revealed that a large scale, multipartner launch of the FC occurred in Ghana in May 2000. The launch was largely successful in raising product awareness; however, uptake remained and currently still remains low. Most stakeholders agree that momentum has waned substantially since the initial launch and report that financial support for large scale promotion and distribution is lacking. Thus, while the product is reportedly available in both the public and private sector, social marketing efforts are virtually absent, pelvic models and information, education, and communication (IEC) materials are limited, distribution primarily occurs in urban areas, and aside from urban sex workers, programmers have limited information about current or prospective FC users. In addition, while the FC has been positioned both as a contraceptive commodity and for protection against HIV and STIs, promotion primarily occurs through the Reproductive and Child Health Department of the Ghana Health Service. Aside from services for commercial sex workers, efforts to integrate FC promotion within a broader range of HIV/AIDS programs appear nascent.

Despite the current lull in activity with regard to FC promotion, interest and nominal support for it at the policy level are high. This is evidenced by the FC's reported inclusion in the reproductive health and HIV/AIDS policy frameworks, service provider guidelines, and revised curricula for in-service training. Furthermore, the majority of interviewed stakeholders has a strong belief in the FC's potential and feels that greater attention and resources should be committed to its promotion. Though stakeholders expressed a number of concerns about past and current FC promotion, overall, the exploratory exercise revealed that the current context and timing offer a relatively strong window of opportunity for enhancing promotion of the product in Ghana. Drawing upon stakeholder suggestions and synthesis of key observations and findings, this report concludes with specific recommendations for moving forward with an initiative to enhance FC promotion. 


\section{1- Introduction}

The Population Council has a long-standing interest in the development and introduction of a range of contraceptive and reproductive health products, particularly those that provide dual protection against pregnancy and sexually transmitted infections and help expand women's choices. In line with this interest, we are currently working in several sub-Saharan African countries to understand and address the programmatic barriers that hinder access to and use of the female condom (FC) - the only safe and effective female-initiated method that provides simultaneous protection against unintended pregnancy as well as sexually transmitted infections, including HIV/AIDS.

Though the female condom is currently available in 108 countries, FC programming mechanisms and levels of uptake vary considerably. Notably successful programs have been launched in Brazil, South Africa, Zambia, and Zimbabwe. Research from these and other countries indicates that effective national promotion of the $\mathrm{FC}$ within the context of $\mathrm{FP} / \mathrm{RH}$ programs has the potential to expand contraceptive choice and add to the overall method mix. ${ }^{1}$ The promotion of the female condom within the context of HIV/AIDS programs (depending on the nature of the epidemic), provides an additional tool in the HIV prevention tool box. Furthermore, it is anticipated that successful promotion of the FC can help pave the way for successful introduction of other prospective female-initiated methods, such as microbicides.

While the FC is currently available in Ghana, uptake is low and a concerted marketing effort is absent. However, it is believed that the following contextual factors may provide a particularly ripe environment for successful future promotion: 1) past interest and experience promoting the $\mathrm{FC}$ at the national level; 2) relatively low contraceptive prevalence rate (19\% -modern methods) $\left.{ }^{2} 3\right)$ high unmet need for family planning $(34 \%)^{2}$; and 4) relatively high HIV prevalence among high risk groups (e.g. $24-52 \%$ among commercial sex workers). ${ }^{3,4}$

To explore the viability of enhancing FC programming in Ghana and to gain an understanding of the current and historical landscape of FC programming, interviews were held with key stakeholders who have intimate knowledge of the Ghanaian FC context or who otherwise play critical roles in national reproductive health and HIV/AIDS programming. A complete list of interviewed stakeholders is provided in Table 1. Individuals and/or organizations were selected on the basis of known involvement in past or current FC initiatives; snowball sampling was then used to identify additional stakeholders. Time limitations precluded the involvement of all relevant stakeholders in this initial exploratory exercise; thus, this sampling is not exhaustive and may be expanded upon as further interest and efforts emerge. 


\section{Table 1:}

\begin{tabular}{|c|c|c|}
\hline Name & Affiliation & Position/Title \\
\hline Manju Chetani & $\begin{array}{l}\text { African Microbicides Advocacy Group } \\
\text { (AMAG) }\end{array}$ & Coordinator \\
\hline Daniel Mensah & $\begin{array}{l}\text { Freedom From Hunger, } \\
\text { Microbusiness for Health }\end{array}$ & Social Franchise/Country Manager \\
\hline Atuahene Kyereme & Ghana AIDS Commission (GAC) & $\begin{array}{l}\text { Ag. Director, Research, Monitoring, } \\
\text { and Evaluation }\end{array}$ \\
\hline Richard Amenyah & Ghana AIDS Commission (GAC) & Director, Technical Services \\
\hline Gloria Quansah Asare & Ghana Health Service, Ministry of Health & Ag. Director, Family Health Unit \\
\hline Rudi Lokko & Ghana Social Marketing Fund (GSMF) & Chief of Operations \\
\hline Egbert Bruce & JSI/DELIVER & Country Director \\
\hline Fred Yao Gbagbo & Marie Stopes International (MSI) - Ghana & Clinical Services Manager \\
\hline Evelyn Quaye & National AIDS Control Programme & $\begin{array}{l}\text { Public Health Nurse, } \\
\text { Care \& Support Unit }\end{array}$ \\
\hline Angelina Kodua Nyanor & National AIDS Control Programme & $\begin{array}{l}\text { Senior Public Health Nurse, } \\
\text { Care \& Support Unit }\end{array}$ \\
\hline Dan Amaning Danquah & Pharmacy Council & Senior Inspecting Pharmacist \\
\hline Akwasi Boakye-Yiadom & $\begin{array}{l}\text { Planned Parenthood Association of } \\
\text { Ghana (PPAG) }\end{array}$ & Director of Programs \\
\hline Janet Kwansah & $\begin{array}{l}\text { Policy, Planning Monitoring and } \\
\text { Evaluation Directorate, Ministry of Health }\end{array}$ & $\begin{array}{l}\text { Head, Monitoring and Evaluation } \\
\text { Unit }\end{array}$ \\
\hline Kobina Bainson & Population Council/Ghana & Chief of Party, CHPS-TA \\
\hline Bernice Heloo & $\begin{array}{l}\text { Society for Women and AIDS in Africa } \\
\text { (SWAA) }\end{array}$ & President, SWAA International \\
\hline Cecilia Lodonu-senoo & $\begin{array}{l}\text { Society for Women and AIDS in Africa } \\
\text { (SWAA) }\end{array}$ & President, SWAA Ghana \\
\hline Sebastian Eliason & United Nations Population Fund (UNFPA) & $\begin{array}{l}\text { National Programme Officer - } \\
\text { Reproductive Health }\end{array}$ \\
\hline Mercy Osei-Konadu & United Nations Population Fund (UNFPA) & National Programme Officer \\
\hline Emmanuel Essandoh & $\begin{array}{l}\text { United States Agency for International } \\
\text { Development (USAID) }\end{array}$ & ACCRA/HPNO \\
\hline Peter Wondergem & $\begin{array}{l}\text { United States Agency for International } \\
\text { Development (USAID) }\end{array}$ & HIVIAIDS Advisor \\
\hline Comfort Adu-Asamoah & $\begin{array}{l}\text { West Africa Program to Combat AIDS } \\
\text { and STI (WAPCAS) }\end{array}$ & Deputy Executive Director \\
\hline
\end{tabular}

Stakeholders Interviewed about the Promotion of the Female Condom in Ghana 
Stakeholders were asked to discuss a wide range of issues regarding the female condom, including but not limited to: procurement mechanisms, supply chain, integration within national policies and strategies, factors affecting demand, service statistics, lessons learned from past promotion efforts, appropriate positioning and target groups, and views on future promotion and social marketing. Discussion topics are outlined in Appendix 1. Notes were taken during each interview and later synthesized to formulate the current report, which aims to outline the historical and current context of the FC in Ghana, challenges with regard to supply and demand, and stakeholders' views on enhancing promotion. The report also offers recommendations for a way forward.

\section{2- Historical Context}

\section{1- Launch of the female condom}

Approved by the U.S. Food and Drug Administration in $1993,{ }^{5}$ the FC was officially launched in Ghana in May 2000 by the Female Condom Planning Committee (FCPC), a collaborative working group including a wide range of stakeholders listed in Table 2. ${ }^{6,7}$ The FCPC developed a multi-faceted strategy for the introduction of the female condom, which primarily involved training of a wide range of providers and distributors, as well as social marketing, development of information, education, and communication (IEC) materials, media messaging, and distribution in a variety of public and private outlets. While there was initially some disagreement about appropriate positioning of the FC, it was ultimately positioned as a "female controlled" dual protection method. Following initial launch activities, the United Nations Population Fund (UNFPA) ordered close to one million female condoms for the Ministry of Health in Ghana. ${ }^{8}$

Among the many successes of the 2000 launch, the most commonly noted were the exceptional level of coordination among stakeholders and the effective training of a broad range of clinical and non-clinical personnel. Most importantly, the 2000 launch was successful in generating widespread public attention. In fact, 83 percent of all women aged 15-49 in the 2003 Demographic and Health Survey (DHS) reported having heard of the female condom. This rate is nearly comparable to awareness of the highly popular injectable and considerably higher than the rates of those having knowledge about the IUD, implants, or diaphragm. Despite this high level of awareness, uptake of the method remained relatively low. In the same survey year, 0.8 percent of married women aged 15-49 who had ever used a contraceptive method reported having ever used the female condom, while 0.1 percent reported current use. Use of the female condom was notably higher among sexually active 
unmarried women, among whom 4.9 and 0.5 percent reported ever use and current use of the female condom, respectively. ${ }^{2}$

\section{Table 2:}

\section{Stakeholders Involved in 2000 Launch of the Female Condom in Ghana}

\begin{tabular}{|l|l|l|}
\hline International Partners & Local Partners & $\begin{array}{l}\text { Trained } \\
\text { Providers/Educators }\end{array}$ \\
\hline UNAIDS & Ministry of Health & Doctors \\
Wemale Health Company & National AIDS Control Program (NACP) & Nurses \\
Reproductive and Child Health Unit & Midwives \\
& Health Education Unit & Nutritionists \\
& SWAA Ghana (Society for Women and & Health Education Officers \\
& AlDS in Africa - Ghana Chapter) & Pharmacists \\
& Planned Parenthood Association of & Secretaries \\
& Ghana (PPAG) & Nursing tutors \\
& Ghana Social Marketing Foundation & Opinion Leaders \\
& (GSMF). & Pharmacists \\
& Ghana Registered Midwives Association & Chemical Sellers \\
& Canadian International Development & Women's Groups \\
& Agency (CIDA) & Midwives \\
& Association for Voluntary Surgical & Clinic \& Outreach Staff \\
& Contraception (AVSC) (now & \\
& EngenderHealth) \\
& Society of Private Medical and Dental & \\
& Practitioners (SPMDP) & \\
\hline
\end{tabular}

Source: GHS PPT Presentation, obtained from Gloria Asare, Ag. Director, Family Health, GHS

When asked about the limitations of the previous launch, stakeholders noted the following key issues:

- Lack of sustained commitment and support following the initial burst of activities;

- Irregular supply at some distribution sites;

- Primary focus on training providers without an equivalent effort to increase demand among potential clients; 
- Overly generalized marketing efforts, thereby diffusing impact for the most appropriate target groups;

- Limited collaboration with and involvement of the mass media; and

- Minimal operational research conducted to inform the launch and to monitor and evaluate progress.

\section{2- Perpetuation of unverified "truths"}

It is important to note that the historical context of the female condom in Ghana is rife with several unverified "truths," which are commonly circulated among the programming community. One such "truth" mentioned by several stakeholders is that at one time, sales of the FC were considerably high, however, the product was not being used as intended. For example, it was repeatedly mentioned that the inner rings of the FC were used as bangles, which in some communities were dyed and sold. At one point, this story even gained national media attention. Other unverified "truths" suggest that the rings were used by seamstresses as reinforcements for clothing and that the $\mathrm{FC}$ was primarily purchased by people from neighboring countries where it was either unavailable or more expensive. While some stakeholders report having debunked these so-called "truths," others maintain their validity. Thus, it remains unclear whether these anecdotes are true (and if so, to what extent), or whether they are myths that have gained legitimacy through verbal repetition. Regardless of where the truth lies, the continued circulation of such "truths" can be discouraging for the programming community and may also undermine the legitimacy of the FC among the general public.

\section{3- Current State of Affairs}

Currently, the FC-1, manufactured by the Female Health Company is reportedly available in both the public and private sectors in Ghana, however, many stakeholders are doubtful of its availability in pharmacies. Anecdotal evidence suggests that uptake is minimal and unlikely to have increased since the 2003 DHS, when only 1 percent of women aged 15-49 who had ever used contraception, reported having ever used the female condom. ${ }^{2}$

Most stakeholders agree that momentum has waned substantially since the initial launch of the FC in 2000 and report that financial support for large scale promotion and distribution is lacking. Thus, while the product is available, social marketing efforts are virtually absent, pelvic models and IEC materials are limited, distribution primarily occurs in urban areas, and programmers have limited information about likely current or prospective FC users. Urban sex workers are the one exception to 
the latter statement, as they are specifically targeted by the West Africa Project to Combat HIV/AIDS and STIs. A 2005 research study offers rich information about perceptions, use, and challenges to use among this group.

While the FC has been positioned both as a family planning commodity and for protection against HIV/STIs, promotion primarily occurs through the Reproductive and Child Health Department of the Ghana Health Service. Aside from services for high risk groups such as commercial sex workers, efforts to integrate FC promotion within a broader range of HIV/AIDS programs appear nascent. Public health nurses at the National AIDS Control Programme (NACP) note that the female condom is routinely mentioned in all provider or peer educator trainings, as well as in voluntary counseling and testing sessions, however, the method is not commonly available for purchase in public facilities where HIV/AIDS services are offered and is generally overshadowed by the male condom. Furthermore, some influential stakeholders feel that it is not cost-effective to promote the female condom for HIV/AIDS prevention.

Several stakeholders expressed disappointment about the current state of affairs with regard to the FC. One individual mentioned that the situation with the female condom has become "business as usual," while another lamented that it is "just hanging." Another stakeholder commented that people have not yet "come to grips" with use of the female condom in Ghana. He added that it is being sold "under the shadow of the male condom." This sentiment was reinforced by yet another stakeholder who expressed concern over the fact that the FC "hasn't been marketed in a big way." In his opinion, this is because "those who brought it did not take it as seriously as they should have."

\section{1- Interest and support for further promotion}

Despite the apparent lull in FC activity, interest and nominal support of the FC at the policy level is high. This is evidenced in part by the FC's reported inclusion in the reproductive health and HIV/AIDS policy frameworks, service provider guidelines, and revised curricula for in-service training. Furthermore, with only one exception, interviewed stakeholders expressed strong consensus about the suitability of the Ghanaian context for further promotion of the female condom and suggested that greater attention and resources be committed to such an effort. In fact, Gloria Asare, Ag. Director of the Family Health Unit at the Ghana Health Service (GHS) mentioned that the GHS has been interested in re-launching both the male and female condom and would welcome any external support to further such an agenda.

The majority of stakeholders believe that appropriate marketing of the female condom is the primary area on which future efforts should focus. They are, however, weary of a "one off" type of 
promotional event, as it is recognized that sustained, long-term commitment is essential for the success of the FC. Furthermore, stakeholders urged that we maintain realistic expectations about uptake of the female condom. This method may not be appropriate for everyone and thus we should not expect uptake to be exceptionally high or comparable to that of the male condom. In addition, it was suggested that successful promotion will require the "programming community" to acknowledge and openly discuss the method's potential drawbacks, rather than brush them aside to focus on other aspects of programming. Finally, stakeholders cautioned that while local community-based projects can aid in identifying best practices, advocacy should begin at the government level. In particular, it was mentioned by one stakeholder that when there is lack of coordination at the national level, the onus is left to those on the ground - which has not been successful in the past. Another succinctly stated that "national action paves the way for local action."

\section{2- Transition to the FC-2}

In 2005, the Female Health Company began manufacturing the FC-2, a new model of the female condom, which is made of nitrile rather than polyurethane. The FC-2 is designed to be less expensive and to lessen noise during use (a common complaint about the FC-1). At present, facilities in Ghana only stock the FC-1. However, the FC-2 has recently been registered with Ghana's Food and Drugs Board and is expected to comprise all upcoming procurements.

\section{4-Procurement, Supply, and Demand}

\section{1- Procurement mechanisms}

Following the initial launch of the female condom in 2000, the Government of Ghana was the primary buyer of female condoms in the country, while UNFPA served as the contracting agent for procurement. However, in 2007, both the government and UNFPA committed funds for the purchase of 200,000 pieces each - 400,000 pieces in total of the FC-2. All FC supplies are procured through the Ministry of Health/Ghana Health Service (MOH/GHS), and then supplied to various distributing agencies through the Central Medical Stores. Primary distributors include the Ghana Social Marketing Fund (GSMF), Planned Parenthood Association of Ghana (PPAG), and the Ghana Registered Midwives Association. While GSMF primarily distributes the FC in the private sector (e.g. to chemical 
sellers), PPAG distributes it through their public clinic facilities, community-based distributors, and NGOs. Within the Ghana Health Service, the FC is primarily sold at WAPCAS supported STI clinics, which target commercial sex workers. Sales are virtually absent at the 1,000 or so other GHS clinics. Figure 1 illustrates the flow of the female condom through the contraceptive commodity supply chain in Ghana.

\section{Figure 1. Supply Chain for the Female Condom in Ghana}

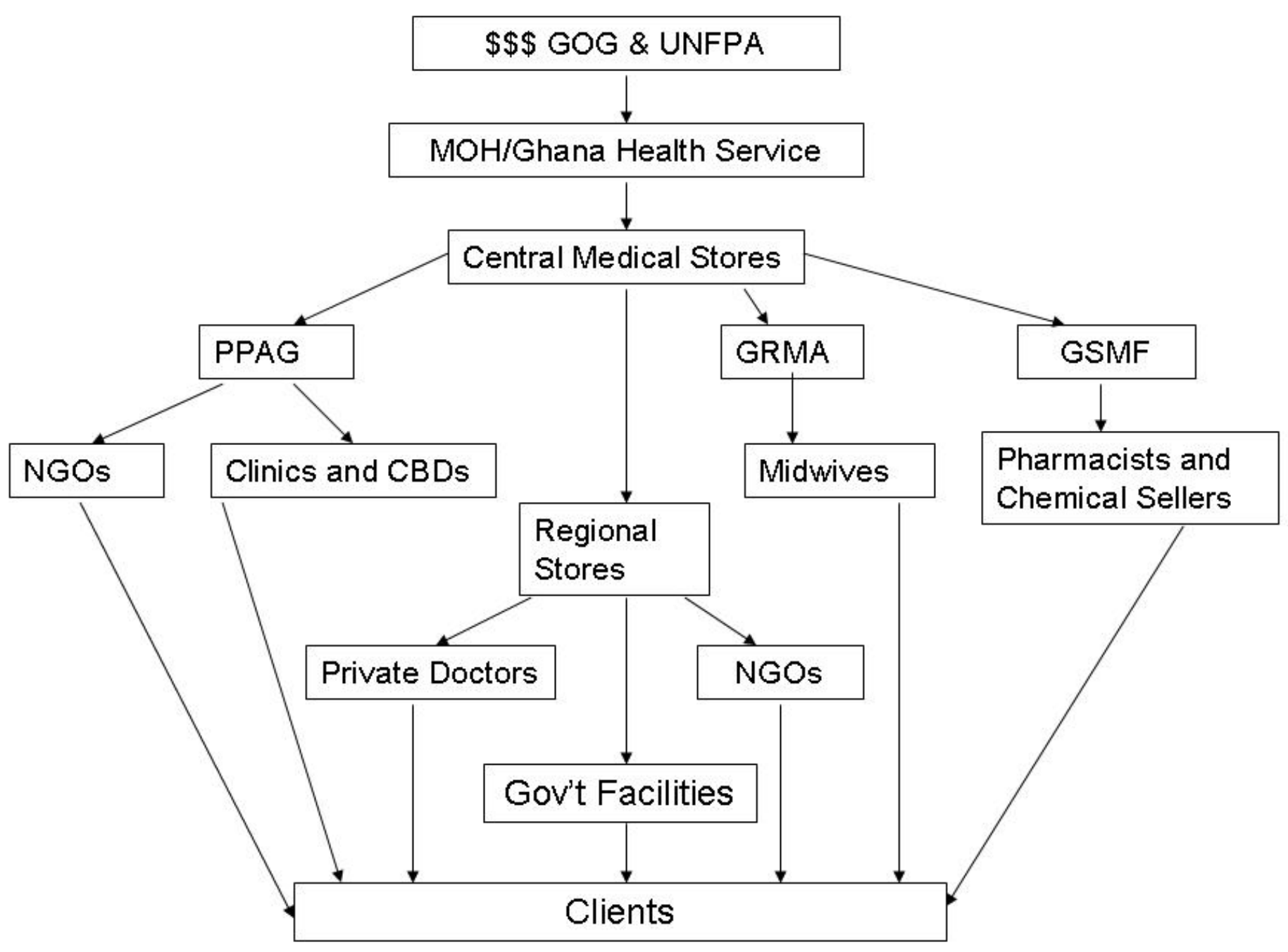


Forecasting for all contraceptive commodities is conducted each year by a core team comprised of JSI/DELIVER, GHS, GSMF, and PPAG. The most recent forecasting exercise took place in midFebruary 2008. Figure 2 illustrates the trend in FC consumption from 2004 to 2007 and the forecasted figures for consumption in 2008. ${ }^{9,10}$

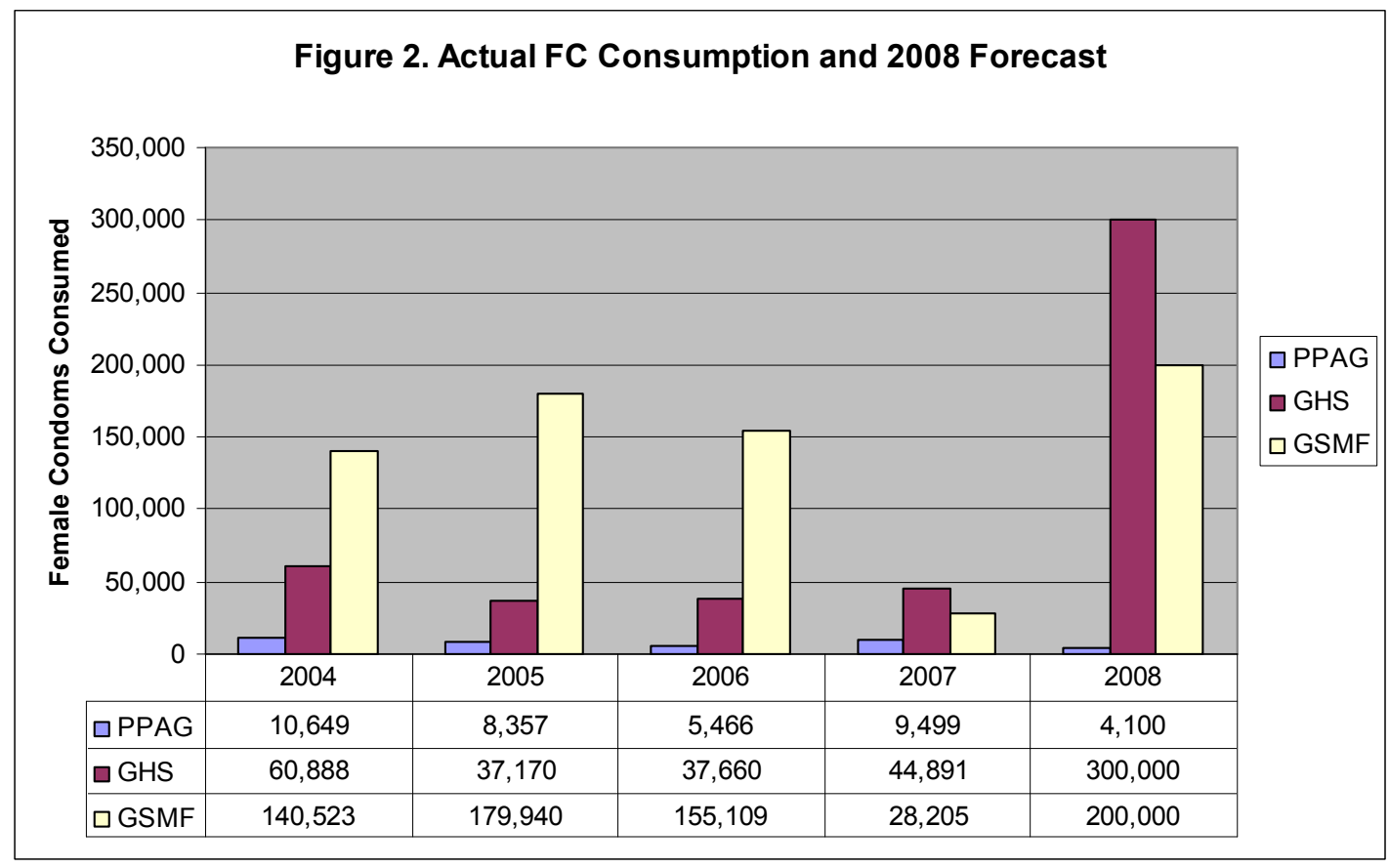

Sources: Ghana Contraceptive Forecast Report, 2007; email communication with Egbert Bruce, Country Director, JSI/DELIVER

Of particular interest in Figure 2 is the forecasted figure for female condom consumption in 2008, which is substantially higher than in previous years. According to Egbert Bruce, Country Director at JSI/DELIVER, this is primarily due to renewed commitment on the part of key stakeholders such as the Government of Ghana, Ghana Health Service, UNFPA, and the Ghana Social Marketing Foundation. Mr. Bruce also notes that stakeholders have a strong belief in the potential for successful distribution and are hopeful that they will receive external support for an extensive FC campaign. In addition, the Ghana Social Marketing Foundation did not operate continuously in 2007 and has plans for more regular operation in the upcoming years. It should be noted that promotion and distribution are currently planned and implemented individually by distributing agencies. 


\section{2- Challenges with regard to demand for the female condom}

Stakeholders noted a number of critical issues, which they believe are responsible for low demand for the female condom:

- Despite high awareness of the FC in the years following the launch, most people currently have limited awareness and knowledge of it, since marketing efforts and product visibility have recently been limited;

- Minimal efforts are in place to identify and target appropriate sub-groups, so information and supply points are generalized, not tailored for the most likely prospective users;

- Though early acceptability studies of the FC in Ghana were positive, many in the provider and programming communities perceive that acceptability is low due to concerns that the product is big, messy, noisy, costly, and cumbersome to use;

- Socio-cultural factors may play a role in dissuading use of the FC. For example, gender dynamics may limit women's ability to negotiate use of a female condom, adolescent girls and women may feel shy to buy the FC for fear of being seen as promiscuous, and females may feel uncomfortable with the idea of having to touch or guide the penis prior to or during intercourse;

- High cost of the FC may deter some prospective buyers, especially youth and others with limited income. Prices vary in the public versus private sector, however, there is at least a 10fold difference in price between male and female condoms.

- Due to a relatively low national HIV prevalence $(2.2 \%),{ }^{5}$ the perceived need for dual protection is low;

- Many couples do not view themselves as the intended users of the FC. For example, some see the FC as a product for commercial sex workers, while others perceive it as something used by the more educated or "elite."

- Many providers have a bias against the FC, often due to negative perceptions about acceptability and lack of personal experience with the product. Thus, providers are likely not promoting or championing the product very actively.

\section{3- Challenges with regard to supply of the female condom}

Stakeholders generally feel that lack of demand for the FC was a more important problem than lack of supply. They did, however, note a few key challenges in ensuring efficient functioning of the drug and contraceptive supply chain. It should be noted that some of these challenges apply to the broader distribution system and may not be specific to the female condom. 
First, capacity and infrastructure for logistics management at the facility level is often limited. Specifically, staff lack computers and appropriate monitoring and evaluation tools for timely and accurate tracking of supplies. Second, lack of transportation poses a significant obstacle, as most regions do not have an appropriate vehicle for the delivery of drugs and contraceptive supplies to facilities. Thus, collection of supplies may be dependent on inconsistent activities, such as travel by district directors or other staff to meetings in the regional capital. Third, difficulties in receiving adequate supplies may encourage some facilities to buy them from the open market, where quality and price may be variable. Fourth, distribution of the female condom has primarily been focused in urban areas, thus supply in rural districts can be inconsistent and limited. Finally, since the female condom is only procured through the public sector at a subsidized price, the private sector has the opportunity to derive a large profit margin. Thus the FC is sold at variable prices. For example, it may be available at Marie Stopes or a public hospital for 500 Cedis, and cost 1,000 Cedis or more in a pharmacy setting.

\section{5- Conclusions and Recommendations}

Overall, this exploratory exercise has revealed that there is a platform for enhancing promotion of the female condom in Ghana. The following contextual factors provide a particularly ripe environment for successful future promotion:

- Relatively low contraceptive prevalence rate $(25 \%$ any method; $19 \%$ modern methods) $;^{2}$

- High unmet need for family planning (34\%); ${ }^{2}$ and

- High HIV prevalence among high risk groups (24-52\% among commercial sex workers). ${ }^{3,4}$

Second, the convergence of the following circumstances suggests that timing for enhanced promotion of the $\mathrm{FC}$ is appropriate:

- The majority of interviewed stakeholders has a strong belief in the product's potential and is supportive of focusing greater attention and resources toward its promotion. 
- The Government and UNFPA are currently in the process of making an exceptionally large procurement of the FC. They are purchasing over 500,000 pieces - a 6-fold increase from 2007 to 2008 .

- The upcoming procurement will entirely be comprised of the new model of the female condom (FC-2). Since this model is expected to be less expensive and more user friendly (e.g. less noisy during use), its upcoming entry into the health system provides an ideal opportunity for re-introduction and promotion.

The current Ghanaian context offers a "window of opportunity" to build momentum and initiate a strong FC promotion agenda. Drawing upon stakeholder suggestions and synthesis of key observations and findings, the following recommendations offer guidance for moving forward with an initiative to enhance FC promotion:

1. Conduct a market analysis to determine commercial sustainability of the FC. Given the historical and current challenges of FC promotion in Ghana, a market analysis should be conducted so as to identify key target groups and geographic regions as well as to establish overall commercial sustainability of the product.

2. Allocate or source funds for implementation of a long-tem FC program. Though extensive funds have been invested in procurement of the $\mathrm{FC}$, past experience shows that product availability and short-term promotion are inadequate for initiating and sustaining wide-scale client interest. Commitment to the FC will require sustained political and financial support for all relevant aspects of product promotion.

3. Establish or designate a committee to develop and implement a strategic plan. In Ghana, distributors currently develop their own FC distribution plans, however, in light of the large upcoming procurement of FC and limited public interest in the product, it will be essential to develop a unified, strategic plan that outlines all relevant activities for promotion and distribution. Participatory development of a national strategy has been essential to the success of FC programs in other settings. A strategic plan could address issues such as key target groups, promotional strategies and social marketing approaches, training of providers and other advocates, and implementation of strategies to ensure efficient flow within the distribution and supply chain. The planning committee could be an existing body, such as the Inter-coordinating Committee for Contraceptive Security (ICC/CS) or one that is newly designated. It is important that the committee include diverse representatives from government, NGOs, advocates, civil society, service delivery, and social marketing. 
4. Review lessons learned. Development of a strategic plan should ensure that key challenges and weaknesses of both male and female condom promotional efforts in Ghana, as well as in the broader, global community are understood and well addressed. Despite differing social and cultural contexts, many of the challenges experienced with regard to male and female condom promotion are universal.

5. Determine rationale for product promotion and develop strategic plan. Stakeholders should reach consensus on why the female condom is needed in Ghana and determine the context in which it will be most effective. This should be used as a basis for developing a strategic plan and identifying specific target groups. Targeting of specific sub-groups is important, as past experience shows that generic marketing may diffuse or even counter the impact for the most likely prospective users. At the same time, it is important to strike a balance between over or narrowly targeting the product, as this may lead to stigmatism or dissociation.

Exploratory work in the Nkwanta District reveals that adolescents and unmarried young adults may be a particularly appropriate target group as they are more likely to take interest in something "new," may have a greater perceived need for dual protection, and may encounter fewer socio-cultural barriers to FC use.

6. Ensure contextually appropriate product marketing and messaging. Marketing and messaging for the FC should be well researched and contextually appropriate. The "women's empowerment" angle is likely to be counter-effective in the Ghanaian context as it may threaten or alienate men. More culturally appropriate messaging might advocate for dual protection and emphasize the short and long-term benefits for both partners (e.g. pleasurable sexual experience and safeguarding clients' future prospects in health, marriage, fertility, education, and career.

7. Develop innovative social marketing strategies. Research should be conducted to inform the development of a multi-faceted social marketing plan. Some suggestions offered by stakeholders to guide this process include: developing local branding and attractive packaging, collaborating with the mass media, developing culturally appropriate information, education, communication materials, enlisting popular figures to serve as product "champions," tapping into existing communication channels (e.g. youth groups, professional groups, interaction between women and sellers of feminine hygiene products), and utilizing testimonials from satisfied users.

8. Move beyond traditional IEC. While traditional IEC materials such as posters and pamphlets are important for any marketing campaign, successful promotion of the FC will require that 
targeted clients are well-equipped not only with appropriate knowledge of the product, but also skills to use it comfortably and effectively (e.g. negotiation with partners and facility in correct insertion and removal).

9. Identify and address weaknesses in the supply chain. It is critical to avoid stock-outs and ensure consistent availability of the FC in all areas where the product is promoted, so that client interest and patronage can be encouraged and sustained.

10. Expand provision beyond urban areas. Previous efforts to launch the FC in Ghana have primarily focused on urban centers. However, rural promotional efforts carried out by organizations such as $\mathrm{SWAA}^{11}$ and recent exploratory work carried out by the Population Council in the Nkwanta District indicate that there is interest and scope for promotion in rural areas. Discussions in the Nkwanta District indicate that targeting youth or young adults in town or market centers may be appropriate.

11. Engage civil society actors to expand FC access. Female condoms are primarily available through clinical providers, and at pharmacy and chemical shops. However, certain barriers (e.g. poor provider attitudes, distance, early closing times, and embarrassment) may hinder prospective clients' patronage of such venues. In order to expand product access, civil society actors should be engaged to distribute female condoms. Youth and young adults who participated in exploratory discussions in the Nkwanta District suggested the following as accessible prospective vendors or distribution sites: hairdressers, barbers, nighttime tea sellers, provision stores, public transportation centers and vehicles, filling stations, hotels, drinking bars, restaurants, roadside food sellers, and public toilets.

12. Conduct social behavioral research. It may be necessary to carry out some operational research in order to inform development of appropriate distribution, education, or marketing strategies for the FC. Some issues to explore as part of such research might include: methods for overcoming cultural barriers that currently discourage use of the FC, identifying appropriate communication channels (existing or new) for specific target groups, debunking myths and misconceptions that may currently discourage use of the $\mathrm{FC}$, developing appropriate language and dialogue around the FC, and developing culturally appropriate strategies to involve men in FC promotion.

13. Target providers first. Providers (e.g. physicians, nurses, and chemical sellers) themselves appear to have a number of negative perceptions about the female condom, as well as limited experience using it. Thus, rather than assume that they will be natural allies for FC promotion, 
providers should be regarded as the initial target group. Only when they are true believers, will providers be effective product champions.

14. Train providers in strategic promotion. Though providers have adequate clinical knowledge about the FC, they lack training in other aspects that are critical in building and sustaining client interest in the product. Thus providers should be trained in areas such as: integrating the FC within education about sexual and reproductive health, selective targeting of client groups, appropriate positioning for different client groups, use of satisfied client testimonials in promotional talks, building client capacity to effectively dialogue with partners, and ensuring clients have the skills and confidence necessary for correct insertion, use, and removal of the product.

15. Target and involve men in promotion. Men in Ghanaian society are commonly regarded as the decision-makers; this holds true within the realm of sexual and reproductive health. Thus men's support of the FC is critical for encouraging joint-decision making and enhancing women's capacity to successfully purchase and/or use it. Exploratory work reveals that promotion among men might involve an emphasis on both the immediate physical benefits (e.g. greater pleasure than the male condom since a preference for "skin to skin" contact appears to deter condom use), as well as on the long term social, health, and financial benefits.

16. Encourage integration within broader context of sexual and reproductive health. Promotion of the FC should not be centered on the product itself, but rather on meeting the sexual and reproductive health needs of prospective clients. Accordingly, the FC should be promoted among key target groups in the context of sexual and reproductive health education, and with equal emphasis to the male condom.

17. Strengthen FC integration within the context of HIV/AIDS programming. The FC should be more actively promoted within the context of HIV prevention, voluntary counseling and testing, and antiretroviral treatment. In particular, it should be made available onsite and promoted alongside the male condom (given equal weight and attention) as an appropriate method for dual protection.

18. Develop and implement a monitoring and evaluation plan. It will be essential to develop a monitoring and evaluation plan, so as to track progress and make necessary adjustments throughout program implementation. Aside from tracking program outputs and outcomes, it may also be helpful to address key operational research questions. 


\section{Appendix 1: Key Questions}

\section{Access, Availability, Acceptability, and Use of the Female Condom in Ghana}

- Is the female condom presently integrated into national health policies (e.g. RH, HIV/AIDS, and pharmaceutical policies, protocols, and strategies)?

- Is the female condom currently integrated into service training curricula (e.g. community health nurses, hospital nurses, physicians)?

- What factors would you say are affecting the supply of female condoms?

- What factors would you say are affecting the demand for female condoms?

- Who (e.g. which organizations, programs, etc.) in the country is procuring female condoms?

- Do we have any idea of the size of the procurement currently and in the past few years?

- Is there one centralized system for distribution or several parallel systems? Describe.

- What is the logistics chain for supply/distribution of female condoms?

- What are the challenges in the functioning of this chain?

- Who (e.g. projects, organizations, clinics) is distributing female condoms?

- In which settings is the female condom being distributed?

- Particular geographic areas?

- Particular population groups?

○ Programmatic/clinical settings (e.g. hospital RH unit, VCT)

$\circ$ Why these settings in particular?

- Is it possible to get any service statistics and trends on distribution from any of these sources?

- How is the female condom currently being positioned (e.g. family planning method, protection from HIV/AIDS, etc)?

- To what extent and under which circumstances is the female condom being offered?

- Is it discussed in all cases where the male condom is mentioned?

- Is it raised in discussions about family planning or do providers wait for clients to ask about it?

- What is the perception regarding interest and acceptability among users?

- What are the challenges to introducing, generating interest, or distributing the female condom?

- What role do you believe the female condom could/should or should not play in Ghana?

- Do you know of any past, current, or upcoming research studies about the female condom?

- Do you know of any upcoming plans or projects relating to the female condom? 


\section{References}

1. The Female Health Company. Available at: http://www.femalehealth.com.

2. Ghana Statistical Service (GSS), Noguchi Memorial Institute for Medical Research (NMIMR), and ORC Macro. 2004. Ghana Demographic and Health Survey 2003. Calverton, Maryland. GSS, NMIR, and ORC Macro.

3. Ghana AIDS Commission. 2008. National Report on the Progress of the United Nations General Assembly Special Session (UNGASS) Declaration of Commitment on HIV and AIDS - Ghana. Accra, Ghana. Ghana AIDS Commission.

4. National AIDS Control Program. Technical Report Estimates and Projections of National HIV Prevalence and Impact in Ghana Using Sentinel Surveillance Data Adjusted with DHS+ Data. 2007. Accra, Ghana. Ghana Health Service, the World Bank, WHO, Constella Futures.

5. Avert. 2007. The Female Condom. Available at: http://www.avert.org/femcond.htm.

6. Health Research Unit, Ghana Health Service (GHS). A Study on the Use of Female Condoms Among Sex Workers in Accra. 2005. Accra, Ghana. West Africa Project to Combat AIDS and STI, GHS, AWARE, and USAID.

7. Ghana Health Service (GHS). Female Condom Presentation. Obtained from Gloria Asare, Ag. Director, Family Health Unit, GHS.

8. Female Health Company. Ghana Orders One Million Female Condoms. March 2001. Available at: http://www.modernghana.com/news/13256/1/Ghana-Orders-One-Million-Female-Condoms.

9. Ministry of Health $(\mathrm{MOH}) / \mathrm{Ghana}$, Academy for Educational Development (AED)/Ghana Sustainable Change Project (GSCP), Ghana Social Marketing Foundation (GSMF), and John Snow Inc./DELIVER/Ghana. Ghana Contraceptive Forecast \& Requirements for the Years 2007, 2008, and 2009 for MOH, AED/GSCP and GSMF. 2007. Accra, Ghana. MOH/Ghana, AED/GSCP, GSMF, JSI/DELIVER/Ghana.

10. Email communication with Egbert Bruce, Country Director, John Snow Inc./DELIVER.

11. Population Council. In Our Own Hands: SWAA-Ghana Champions the Female Condom. 2006. New York. Population Council.

12. Brady, Martha. "A New Wave of Programming for Women's Protection Products", presented at the Global Consultation on the Female Condom, Baltimore, September 26-29, 2005 